\title{
Serum from Chronic Hepatitis B Patients Promotes Growth and Proliferation via the IGF-II/IGF-IR/MEK/ERK Signaling Pathway in Hepatocellular Carcinoma Cells
}

\author{
Yuanyuan Jia Zhidong Wang ${ }^{b}$ Haiyan Chen ${ }^{a}$ Lei Zhang ${ }^{c} \quad$ Fei Zhuo \\ Qingqing Yanga
}

aScientific Research Centre, 'Department of VIP General Surgery, cMedical Clinical Laboratory, The Second Affiliated Hospital, Xi'an Jiaotong University, Xi'an, China

\section{Key Words}

Hepatitis B virus (HBV) - Insulin-like growth factor-II (IGF-II) - Growth • Proliferation • Hepatocellular carcinoma (HCC)

\begin{abstract}
Background/Aims: Chronic hepatitis B virus (HBV) infection (CHB) plays a central role in the etiology of hepatocellular carcinoma (HCC). Emerging evidence implicates insulin-like growth factor (IGF)-II as a major risk factor for the growth and development of HCC. However, the relationship between HBV infection and IGF-II functions remains to be elucidated. Methods: Levels of circulating IGF-II and IGF-I receptor (IGF-IR) in healthy donors (HDs) and CHB patients were tested by ELISA. Human HCC cell lines (HepG-2, SMMC-7721, MHCC97-H) were incubated with serum from $\mathrm{HDs}$ and $\mathrm{CHB}$ patients at various concentrations for 24,48 , and 72 h. MTT and plate colony formation assays, BrdU ELISA, ELISA, small-interfering RNA (siRNA) transfection, quantitative real-time $P C R$, and western blot were applied to assess the functional and molecular mechanisms in HCC cell lines. Results: Serum levels of IGF-II and IGF-IR were significantly higher in $\mathrm{CHB}$ patients than in $\mathrm{HDs}$. Additionally, serum from $\mathrm{CHB}$ patients directly induced cell growth, proliferation, IGF-II secretion, and HDGF-related protein-2 (HRP-2) and nuclear protein 1 (NUPR1) mRNA and protein expression in HCC cells. Moreover, serum from CHB patients increased IGF-II-induced cell growth, proliferation, and HRP-2 and NUPR1 mRNA and protein expression in HCC cells. Blockade of IGF-IR clearly inhibited the above effects. Most importantly, interference with IGF-II function markedly repressed the cell proliferation and HRP-2 and NUPR1 mRNA and protein expression induced by serum from CHB patients. Furthermore, serum from CHB patients induced ERK phosphorylation via IGF-IR, with the MEK inhibitor PD98059 significantly decreasing CHB patient serum-induced IGF-II secretion, cell proliferation, and HRP-2 and NUPR1 mRNA and protein expression. Conclusion: Serum from CHB patients increases cell growth and proliferation and enhances HRP-2 and NUPR1 expression in HCC cells via the IGF-II/IGF-IR/MEK/ERK signaling pathway. These findings help to explain the molecular mechanisms underlying HBV-related HCC and may lead to the development of effective therapies.

(C) 2018 The Author(s)

Published by S. Karger AG, Base

Zhidong Wang

Department of VIP General Surgery, The Second Affiliated Hospital, Xi'an Jiaotong University, No. 157 West $5^{\text {th }}$ Road, Xi'an 710004, Shaanxi (China)

Tel. +8629 87679208, Fax +862987678330, E-Mail xawzd@163.com
\end{abstract}

KARGER 


\section{Cellular Physiology Cell Physiol Biochem 2018:47:39-53

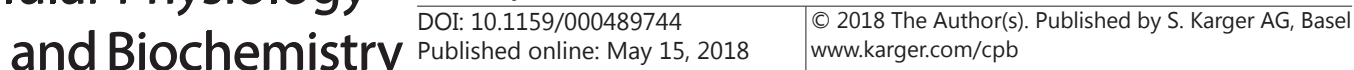

Ji et al.: CHB Promotes Proliferation via IGF-II in HCC

\section{Introduction}

Hepatocellular carcinoma (HCC) is the fifth most common cancer worldwide [1]. Chronic hepatitis B virus (HBV) infection (CHB) is a significant predisposing factor for hepatitis and cirrhosis [2]. In addition, chronic HBV infection has a well-documented association with HCC [3], with strong geographic correlation demonstrated between the prevalence of CHB and the incidence of HCC. Globally, it has been estimated that 54\% of HCC cases can be attributed to HBV infection [4]. HBV infection has a complex natural history, centered on the liver, where the interaction between viral proteins and the immune system leads to a cycle of hepatocyte damage and tissue repair [5]. The X protein (HBx) encoded by HBV is believed to be the major player in HBV-induced oncogenesis [6, 7]. HBx is also reported as a multifunctional viral protein that regulates cell proliferation, differentiation, and apoptosis $[8,9]$.

HBV infection is involved in the degeneration, necrosis, and cirrhosis of liver cells, which leads to abnormal activation of the insulin-like growth factor (IGF)-II gene and IFG-I receptor (IGF-IR), stimulating aberrant division and unlimited growth of liver cells via the autocrine or paracrine system [10]. IGF-II overexpression can be detected in HCC patients with HBV infection [11]. IGF-II plays a crucial role in the early proliferation of initiated tumor progenitor cells and hepatocarcinogenesis in these patients, and reactivation of fetal P3 and P4 promoters is an important feature in Chinese HCC patients with HBV infection [10].

Emerging evidence confirms that IGF-II is associated with HCC proliferation, migration, and invasion $[12,13]$. Moreover, our previous study also indicated that IGF-II might induce the growth and proliferation of hepatoma carcinoma cells and that IGF-II silencing impairs cell proliferation in human SMMC-7721 cells [14]. HBV infection has been considered the major risk factor for HCC. However, the relationship between HBV infection and IGF-II function remains unknown. The objective of the present study was thus to explore whether serum from CHB patients could promote the cell growth and proliferation of human HCC cells via IGF-II.

\section{Materials and Methods}

\section{Reagents}

Dulbecco's modified Eagle's medium (DMEM) and fetal bovine serum were purchased from Gibco BRL (Carlsbad, CA, USA). IGF-II, PD98059, and methylthiazol tetrazolium (MTT) were provided by Sigma (St. Louis, MO, USA). Picropodophyllin (PPP) was produced by Calbiochem (San Diego, CA, USA). Polyclonal anti-human HDGF-related protein 2 (HRP-2), nuclear protein 1 (NUPR1), and anti- $\beta$-smooth muscle actin antibodies were supplied by Abcam (Cambridge, UK). Phospho-ERK, ERK, phospho-PI3K, and PI3K antibodies were obtained from Cell Signaling Technology (Danvers, MA, USA). Human IGF-II ELISA kits were obtained from Invitrogen (Carlsbad, CA, USA). The BrdU ELISA kit was provided by Maiyueer Bioengineering Institute (Shanghai, China). Small-interfering RNA (siRNA) specific for IGF-II (siGENOME SMARTpool, M-004093-01-0005), negative control siRNA (siGENOME Non-Targeting siRNA Pool, D-001206-13-05), and DharmaFECT 4 transfection reagent (T-2002-04) were purchased from Dharmacon (Lafayette, CO, USA).

\section{Patient samples}

Peripheral blood samples and clinical assessments were obtained during routine follow-up of hepatitis patients. CHB patients in the immune-tolerant phase were admitted to the Second Affiliated Hospital of Xi'an Jiaotong University. All patients were negative for other viral infections, including HCV, HIV, and hepatitis D virus, and had no autoimmune liver diseases. An age- and sex-matched control group was composed of healthy donors (HDs). The clinical characteristics of these samples are described in Table 1. In accordance with the Ethics Committee of the Second Affiliated Hospital of Xi'an Jiaotong University, informed consent was acquired from all participants.

Serum samples were collected from HDs and CHB patients in accordance with the standard protocol. Whole blood samples $(10 \mathrm{ml})$ were collected from CHB patients and HDs in tubes. After collection, the samples were left undisturbed to allow the blood to clot at room temperature. The clots were removed 


\section{Cellular Physiology Cell Physiol Biochem 2018;47:39-53 \begin{tabular}{l|l|l} 
DOI: 10.1159/000489744 & O 2018 The Author(s). Published by S. Karger AG, Basel \\
www.karger.com/cpb
\end{tabular} Ji et al.: CHB Promotes Proliferation via IGF-II in HCC}

by centrifugation at $1500 \mathrm{~g}$ for $10 \mathrm{~min}$ in a refrigerated centrifuge. The resultant supernatants were designated sera and were collected with pipettes in tubes and stored at $-70^{\circ} \mathrm{C}$ until their use.

\section{Cell culture}

Human MHCC97H cells, a typical HCC cell line with high metastatic potential [15], were supplied by the Liver Cancer Institute of Fudan University (Shanghai, China). HepG-2 and SMMC-7721 cell lines were supplied by the American Type Culture Collection (ATCC). These cell lines were authenticated by STR DNA analysis (Genetica DNA Laboratories ) and were found to be mycoplasma-free (Lonza, Walkersville, MD USA). All cell lines were cultured with DMEM supplemented with $10 \%$ fetal bovine serum and antibiotics at $37^{\circ} \mathrm{C}$ in a $5 \% \mathrm{CO} 2$ humidified atmosphere.

In further experiments, HCC cells were incubated for the indicated times in DMEM supplemented with $10 \%$ HD serum or $10 \%$ CHB patient serum, as described previously $[16,17]$.

\section{MTT assay}

Human HCC cell lines (HepG-2, SMMC-7721, MHCC97-H) were seeded into 96-well plates at a density of $2 \times 10^{4}$ cells/well and incubated with serum from HDs (10\%) or CHB patients (10\%) for 24, 48, and 72 h. Cell viability was analyzed by an MTT assay. At the indicated time points, $20 \mu \mathrm{l}$ of MTT solution (5 mg/ $\mathrm{ml}$ ) was added to each well and incubated at $37^{\circ} \mathrm{C}$ for $4 \mathrm{~h}$. Then, the medium was replaced with $150 \mu \mathrm{l}$ of dimethyl sulfoxide. The absorbance of each well was measured in an enzyme immunoassay analyzer at 490 $\mathrm{nm}$. Experiments were performed at least three times independently.

\section{BrdU ELISA}

Proliferation was assessed as described previously [18]. Briefly, equal numbers of HepG-2, SMMC-7721, and MHCC97-H cells were plated in 96-well plates and serum-starved overnight. Serum starvation induced cell cycle synchronization, meaning that most of the cells stayed in the G1/S transition stage just before $S$ phase entry. Human HCC cell lines were seeded into 96-well plates at $1 \times 10^{4}$ cells/well and incubated with serum from HDs (10\%) and CHB patients (10\%) for 24, 48, and $72 \mathrm{~h}$. Cells were treated with BrdU labeling reagent for $2 \mathrm{~h}$, then the marking liquid was added, and incubated at $60^{\circ} \mathrm{C}$ for $1 \mathrm{~h}$. Then, $200 \mu \mathrm{l}$ FixDenat was added and left for $30 \mathrm{~min}$ at room temperature. Next, $100 \mu \mathrm{l}$ BrdU-POD solution was added, left for 90 min at room temperature, and $100 \mu \mathrm{l}$ substrate solution was added and left for $30 \mathrm{~min}$ at room temperature. Results were quantified by measuring the absorbance at $370 \mathrm{~nm}$. Experiments were performed at least three times independently.

\section{Plate colony formation assay}

Human HCC cell lines (HepG-2, SMMC-7721, MHCC97-H) were seeded into 6-well plates at a density of 200 cells/well. After 10 days, cells were incubated with serum from HDs (10\%) and CHB patients (10\%) for $48 \mathrm{~h}$. Then, cells were washed with PBS, fixed in 10\% methanol for $15 \mathrm{~min}$, and stained with crystal violet for $10 \mathrm{~min}$. Visualized colonies were then photographed and scored. Experiments were repeated at least three times.

\section{ELISA}

Human HCC cell lines (HepG-2, SMMC-7721, MHCC97-H) were seeded into 6-well plates at a density of $5 \times 10^{5}$ cells/well and then incubated with serum from HDs (10\%) and CHB patients $(10 \%)$ for the indicated times. In another experiment, the cells were pretreated with the IGF-IR inhibitor PPP (10 $\mu \mathrm{M})$ for $1 \mathrm{~h}$ and stimulated with serum from HDs or CHB patients for $48 \mathrm{~h}$. Furthermore, after application of MEK inhibitor 


\section{Cellular Physiology Cell Physiol Biochem 2018:47:39-53 and Biochemistry Published onlIne: IVay 15, $2018 \quad \begin{aligned} & \text { DOI: 10.1159/000489744 } 2018 \text { The Author(s). Published by S. Karger AG, Basel } \\ & \text { www.karger.com/cpb }\end{aligned}$}

Ji et al.: CHB Promotes Proliferation via IGF-II in HCC

PD98059 $(1 \mu \mathrm{M})$ for $1 \mathrm{~h}$, cells were stimulated with serum from HDs or CHB patients for $48 \mathrm{~h}$. IGF-II levels in the supernatant were measured with ELISA kits according to the manufacturer's instructions. Each assay was done in triplicate.

\section{Small-interfering RNA transfection}

As described previously [14], cells $\left(1 \times 10^{5}\right)$ were seeded into 6-well plates and were grown until 60$80 \%$ confluent. The cells were transiently transfected with $50 \mathrm{nM}$ of IGF-II siRNA or negative control siRNA (NC siRNA) using DharmaFECT 4 transfection reagents according to the manufacturer's instructions. After $48 \mathrm{~h}$, protein expression and mRNA levels of IGF-II were detected by western blot, quantitative real-time polymerase chain reaction (PCR), and reverse transcription PCR (RT-PCR). Transfection rates of 60-70\% were accepted for all experiments.

\section{Quantitative real-time PCR and RT-PCR}

mRNA levels were determined by our previous method [19]. Total RNA was isolated using a TRIzol Kit (Invitrogen Corp., Carlsbad, CA, USA). cDNA was synthesized from $1 \mu \mathrm{g}$ samples of total RNA using PrimeScript ${ }^{\mathrm{TM}}$ RT Master Mix Kit (Takara, Japan) following the manufacturer's instructions. Real-time PCR was performed with the SYBR Premix Ex Taq ${ }^{\text {TM }}$ II Perfect Real Time kit (Takara) on an ABI QPCR System (Applied Biosystems, Carlsbad, CA, USA) following the manufacturer's instructions. The samples were run in triplicate. Primers for human HRP-2, NUPR1, IGF-II, and $\beta$-actin were designed with Beacon designer version 4.0 (Premier Biosoft, South San Francisco, CA USA). The HRP-2 mRNA sequences were as follows: sense 5'-CCTCCGCCGACAGCATGCCG-3', antisense 5'-GGCTGGAGCTCAGCTGTCCT-3'. The NUPR1 mRNA sequences were as follows: sense $5^{\prime}$-GCCACCTTCCACCAGCAAC- $3^{\prime}$, antisense $5^{\prime}$-CAGCGCTTCACCATGGC- $3^{\prime}$. The IGFII mRNA sequences were as follows: sense $5^{\prime}$-TTGTCCCTCTCCTCCTCCAC- $3^{\prime}$, antisense $5^{\prime}$-TATTAGCAGT CACCACCAAA GCA-3'. The $\beta$-actin mRNA sequences were as follows: sense $5^{\prime}$-TGGCACCCAG CACAATGAA- $3^{\prime}$, antisense 5'-CTAAGTCATAGTCCGCCTAGAAGCA-3'. Traditional PCR was performed according to the manufacturer's instructions. The RT-PCR products were analyzed by electrophoresis through $2 \%$ agarose gels containing ethidium bromide. A melting point dissociation curve generated by the instrument was used to confirm that only a single product was present. Relative gene expression was quantified by the comparative $\mathrm{Ct}$ method $\left(2^{-\Delta \Delta \mathrm{CT}}\right)$ as described by the manufacturer. Data were normalized to human $\beta$-actin mRNA levels. Three independent experiments were carried out to study mRNA levels.

\section{Western blot}

As described previously [19], protein samples $(25 \mu \mathrm{g})$ were separated on sodium dodecyl sulfatepolyacrylamide gel electrophoresis gels and transferred onto a polyvinylidene difluoride membrane (BioRad Laboratories, Hercules, CA, USA). The membranes were blocked with 5\% nonfat dry milk in Trisbuffered saline containing 0.1\% Tween 20 and incubated with specific antibodies against HRP-2 (1:500), NUPR1 (1:1000), phospho-ERK (1:2000), ERK (1:1000), phospho-PI3K (1:1000), PI3k (1:1000), and $\beta$-actin (1:1000). $\beta$-actin was used as a loading control. Reagents (Pierce Corp., Rockford, IL, USA) for the enhanced chemiluminescence were applied to the blots and the light signals were detected by X-ray film. The optical densities of the bands were scanned and quantified with Syngene Gene Tools (Syngene Corp., Cambridge, UK). Three independent experiments were carried out to study protein expression.

\section{Statistical analysis}

All data are expressed as the mean \pm SEM. A Student's $t$ test or one- or two-way analysis of variance (ANOVA) test was used to determine the significance among groups. A value of $p<0.05$ was considered to be statistically significant.

\section{Results}

Circulating IGF-II and IGF-IR levels are higher in CHB patients than in HDs

The mean serum levels of IGF-II were significantly higher in CHB patients than in HDs $(323.26 \pm 36.55 \mathrm{ng} / \mathrm{ml} v s .156 .78 \pm 40.82 \mathrm{ng} / \mathrm{ml}, p<0.01)$. Likewise, the mean serum levels 
of IGF-IR were significantly higher in CHB patients than in HDs $(354.10 \pm 57.58 \mathrm{ng} / \mathrm{ml} v s$. $186.61 \pm 52.41 \mathrm{ng} / \mathrm{ml}, p<0.05$ ) (Table 2).

Serum from HDs and CHB patients induces cell growth and proliferation in HCC cell lines

To study whether serum from HDs and CHB patients is related to the growth and proliferation of HCC cell lines (HepG-2, SMMC-7721, MHCC97-H), we first performed an MTT assay. Compared with control, HCC cell lines treated with serum from HDs and CHB patients showed higher time-dependent growth. In addition, serum from HDs and CHB patients significantly increased tumor cell viability at $72 \mathrm{~h}$ (Fig. 1A).

To evaluate the effect of serum from HDs and CHB patients on HCC cell proliferation, a BrdU ELISA was performed. Compared with control, HCC cell lines treated with serum from HDs and CHB patients showed higher time-dependent proliferation. In addition, serum from HDs and CHB patients significantly increased tumor cell proliferation at $72 \mathrm{~h}$ (Fig. 1B). We further analyzed the colony formation ability of HCC cell lines treated with serum from HDs and CHB patients using crystal violet staining. Compared with control, colony number was markedly increased after cells were treated with serum from HDs and CHB patients. In addition, serum from HDs and CHB patients significantly increased tumor cell proliferation (Fig. 1C and D). The results showed that serum from HDs and CHB patients induced HCC cell growth and proliferation in a time-dependent fashion. However, the induction of serum from CHB on cell growth and proliferation was

Table 2. Levels of circulating IGF-II and IGF-IR in chronic hepatitis B patients and healthy donors. Compared with the HD group, ${ }^{*} p<0.05$, $* * p<0.01$. Abbreviations: CHB, chronic hepatitis B virus infection; HDs, health donors; IGF-II, insulin-like growth factor II; IGF-IR, insulin-like growth factor-I receptor

\begin{tabular}{lccc}
\hline & No. of cases & IGF-II $(\mathrm{ng} / \mathrm{ml})$ & IGF-IR $(\mathrm{ng} / \mathrm{ml})$ \\
\hline HDs & 46 & $156.78 \pm 40.82$ & $186.61 \pm 52.41$ \\
CHB & & & \\
patients & 54 & $323.26 \pm 36.55^{* *}$ & $354.10 \pm 57.58^{*}$ \\
\hline
\end{tabular}
significantly stronger than serum from HDs.

Fig. 1. Effects of serum from healthy donors (HDs) and chronic hepatitis B virus infection (CHB) patients on cell growth and proliferation in HCC cell lines (HepG-2, SMMC-7721, MHCC97H). (A) The relative viability of HCC cell lines was determined by MTT assay at different time points $(24,48$, and $72 \mathrm{~h}$ ) after application of serum from HDs and CHB patients (10\%). (B) The relative proliferation of HCC cell lines was measured by BrdU ELISA at different time points $(24,48$, and $72 \mathrm{~h}$ ) after application of serum from HDs and CHB patients (10\%). (C) Representatives images of colony formation are shown. (D) The clonal formation efficiency of cells is expressed as the number of colonies formed/200 cells seeded. Data are presented as the mean \pm SEM from three independent experiments. Statistical significance was calculated using Student's t test. ${ }^{*} \mathrm{p}<0.05,{ }^{* *} \mathrm{p}<0.01$ vs. control.

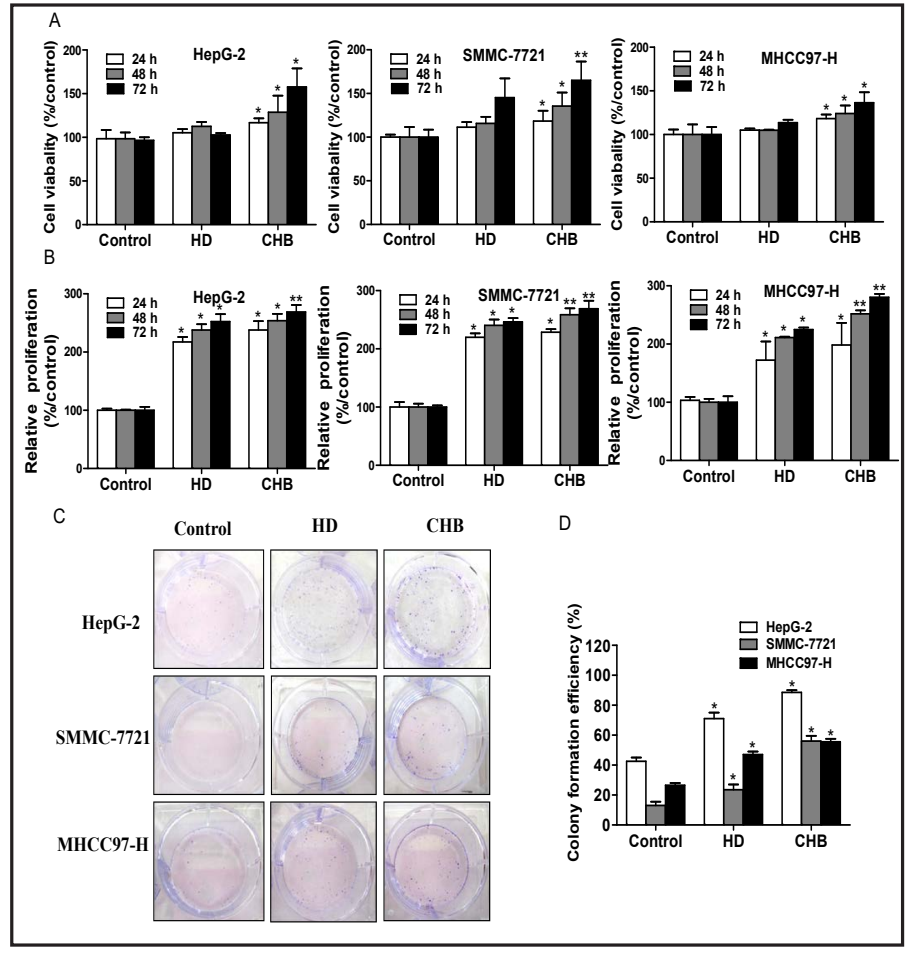


Serum from HDs and CHB patients induces IGF-II secretion in HCC cell lines

To explore the effects of serum from HDs and CHB patients on IGF-II secretion in HCC cell lines (HepG-2, SMMC-7721, MHCC97-H), cells were incubated with serum from HDs and $\mathrm{CHB}$ patients for 24,48 , and 72 h. Serum from HDs and CHB patients increased IGF-II

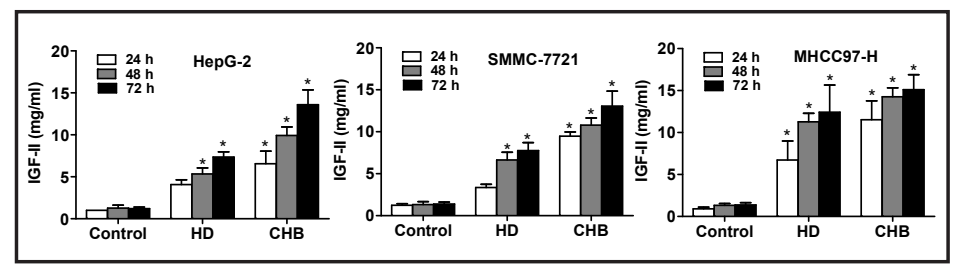

Fig. 2. Serum from HDs and CHB patients induces IGF-II secretion in HCC cell lines (HepG-2, SMMC-7721, MHCC97-H). Cells were incubated with serum from HDs and CHB patients (10\%) for 24,48 , and $72 \mathrm{~h}$. IGFII concentrations in the supernatant were measured by ELISA. Data are presented as the mean \pm SEM from three independent experiments. Statistical significance was calculated by Student's t test. *p $<0.05$ vs. control. secretion in HCC cells in a time- and concentration-dependent manner (Fig. 2).

Serum from CHB patients promotes IGF-II-induced cell growth and proliferation in HCC cell lines

Our previous study found that IGF-II (100 ng/ml) could slightly induce cell growth and proliferation in HCC cell lines (HepG-2, SMMC-7721, MHCC97-H). Thus, to investigate the effect of serum from HDs and CHB patients on IGF-II-induced cell growth and proliferation in HCC cell lines, cells were incubated with IGF-II ( $200 \mathrm{ng} / \mathrm{ml})$ and serum from HDs and CHB patients for 24, 48, and $72 \mathrm{~h}$; MTT assays and BrdU ELISA were then performed. Compared with control, HCC cell lines treated with IGF-II showed cell growth and proliferation. Compared with the IGF-II group, HCC cell lines treated with serum from CHB patients showed higher time-dependent cell growth and proliferation. In addition, serum from CHB patients significantly increased tumor cell growth and proliferation at $72 \mathrm{~h}$. However, application of serum from HDs resulted in a minimal increase in HCC cell growth and proliferation. Moreover, compared with the IGF-II group, the colony number was significantly increased after treatment of cells with serum from HDs and CHB patients (Fig. 3).

Serum from CHB patients promotes IGF-II-induced HRP-2 and NUPR1 mRNA and protein expression in HCC cell lines

We further investigated the effect of serum from HDs and CHB patients on IGF-IIinduced growth and proliferation in HCC cell lines (HepG-2, SMMC-7721, MHCC97-H). Cells were incubated with IGF-II (200 ng/ml) and serum from HDs and CHB patients for $48 \mathrm{~h}$, and HRP-2 and NUPR1 mRNA and protein expression levels were analyzed by quantitative realtime PCR and western blot. As shown in Fig. 4, compared with control, HRP-2 and NUPR1 mRNA and protein expression levels in HCC cells were significantly increased by treatment with serum from CHB patients and IGF-II. Compared with the IGF-II group, HRP-2 and NUPR1 mRNA and protein expression levels in HCC cells were significantly increased by treatment with serum from HDs and CHB patients.

Serum from HDs and CHB patients induces IGF-II secretion and cell growth and proliferation via IGF-IR in HCC cell lines

The above results suggested that serum from HDs and CHB patients might induce IGF-II secretion and cell growth and proliferation in HCC cell lines. To evaluate the role of IGF-IR in the process, we further assessed the effects of pretreatment with PPP, an inhibitor of IGF-IR, on IGF-II secretion and cell growth and proliferation in HCC cell lines treated with serum from HDs and CHB patients. As shown in Fig. 5, $10 \mu \mathrm{M}$ of PPP markedly blocked the effect of serum from HDs and CHB patients on IGF-II secretion and cell growth and proliferation in HCC cell lines. Accordingly, these results demonstrated that serum from HDs and CHB patients induced IGF-II secretion and cell growth and proliferation via IGF-IR in HCC cells. 
Fig. 3. Serum from CHB patients promotes IGF-II-induced growth and proliferation in HCC cell lines (HepG2, SMMC-7721, MHCC97-H). (A) The relative viability of HCC cell lines was determined by MTT assay at different time points $(24,48$, and $72 \mathrm{~h})$ after application of serum from HDs and CHB patients (10\%). (B) The relative proliferation of HCC cell lines was measured by BrdU ELISA at different time points $(24,48$, and $72 \mathrm{~h})$ after application of serum from HDs and CHB patients (10\%). (C) Representative images of colony formation are shown. (D) The clonal formation efficiency of cells is expressed as the number of colonies formed/200 cells seeded. Data are presented as the mean \pm SEM from three independent experiments. Statistical significance was calculated using Student's t test. ${ }^{*} \mathrm{p}<0.05$ vs. control; ${ }^{\#} \mathrm{p}<0.05$ vs. IGF-II; ${ }^{*} \mathrm{p}<0.05$ vs. HDs.

Fig. 4. Serum from $\mathrm{CHB}$ patients promotes IGF-II-induced HRP-2 and NUPR1 mRNA and protein expression in HCC cell lines (HepG-2, SMMC-7721, MHCC97-H). Cells were incubated with serum from HDs and CHB patients and IGF-II (50 ng/ml) for $48 \mathrm{~h}$. (A) HRP-2 and NUPR1 mRNA levels were analyzed by quantitative real-time PCR after normalization to $\beta$-actin mRNA. (B) HRP-2 and NUPR1 protein expression levels were measured by western blot. Data are presented as the mean \pm SEM from three independent experiments. Statistical significance was calculated using Student's t test. ${ }^{*} \mathrm{p}<0.05$, ${ }^{* *} \mathrm{p}<0.01$ vs. control; ${ }^{\#} \mathrm{p}<0.05$, \#\# $\mathrm{p}<0.01$ vs. IGF-II; ${ }^{\& \&} \mathrm{p}<0.01, \quad{ }^{\& \&} \mathrm{p}<0.001$ vs. HDs.
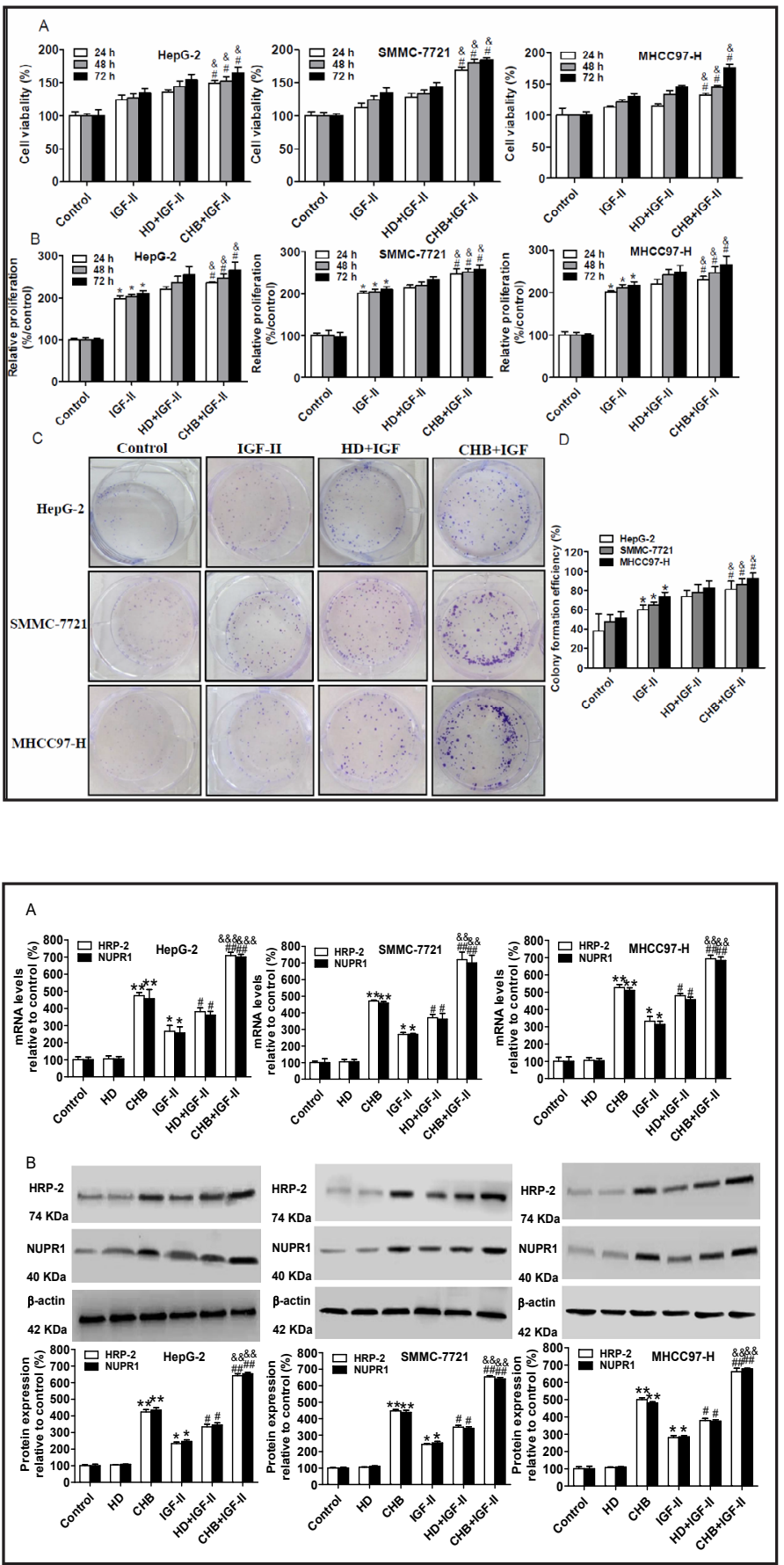

Serum from CHB patients induces HRP-2 and NUPR1 expression via IGF-IR in HCC cell lines

To probe the role of IGF-IR in this process, we further investigated the effects of pretreatment with the IGF-IR inhibitor PPP on HRP-2 and NUPR1 mRNA and protein expression levels in HCC cell lines treated with serum from HDs and CHB patients. As shown in Fig. 6, $10 \mu \mathrm{M}$ of PPP markedly reduced the effect of serum from CHB patients on HRP-2 and NUPR1 mRNA and protein expression in HCC cell lines. Thus, these results suggested that serum from CHB patients induced HRP-2 and NUPR1 mRNA and protein expression via IGF-IR in HCC cells. 
IGF-II SiRNA decreases the effect of serum from HDs and CHB patients on cell proliferation and HRP-2 and NUPR1 mRNA and protein expression in HCC cell lines

Given that the IGF-IR inhibitor PPP decreased the inductive effects of serum from HDs and CHB patients on cell proliferation and HRP-2 and NUPR1 mRNA and protein expression in HCC cell lines, we further analyzed the impact of IGF-II deficiency on these effects of the sera. We transiently transfected cells with IGF-II siRNA for $48 \mathrm{~h}$ and then measured IGFII mRNA and protein expression levels. The knockdown efficiencies of IGF-II were $75.50 \%$ (HepG-2), 75.83\% (SMMC-7721), and 75.00\% (MHCC97-H) on quantitative real-time PCR and 76.33\% (HepG-2), 77.67\% (SMMC-7721), and 74.00\% (MHCC97-H) on western blot (Fig. 7A and B). These results suggested that the silencing efficiency of HCC cells was acceptable for all experiments.

Next, the transfected cells were stimulated with serum from HDs and CHB patients for $48 \mathrm{~h}$. As described in Fig. 7C, compared with the negative control, stimulation of cells with serum from HDs and CHB patients increased cell proliferation, whereas a lack of IGF-II dramatically decreased the inductive effects of serum from HDs and CHB patients on cell proliferation in HCC cell lines, further suggesting that serum from HDs and CHB patients

Fig. 5. Serum from HDs and CHB patients induces IGF-II secretion and cell growth and proliferation via IGF-IR in HCC cell lines (HepG-2, SMMC-7721, MHCC97-H). Cells were pretreated with PPP (10 $\mu \mathrm{M})$ for $1 \mathrm{~h}$ and stimulated with serum from HDs and CHB patients for $48 \mathrm{~h}$. (A) IGF-II concentrations in the supernatant were measured by ELISA. (B) The relative viability of HCC cell lines was determined by MTT assay. (C) The relative proliferation of HCC cell lines was assayed by BrdU ELISA. (D) The clonal formation efficiency of cells was also determined. Data are presented as the mean \pm SEM from three independent experiments. Significance was determined by one-way ANOVA. ${ }^{*} \mathrm{p}<0.05$ vs. control; ${ }^{*} \mathrm{p}<0.05$ vs. PPP.

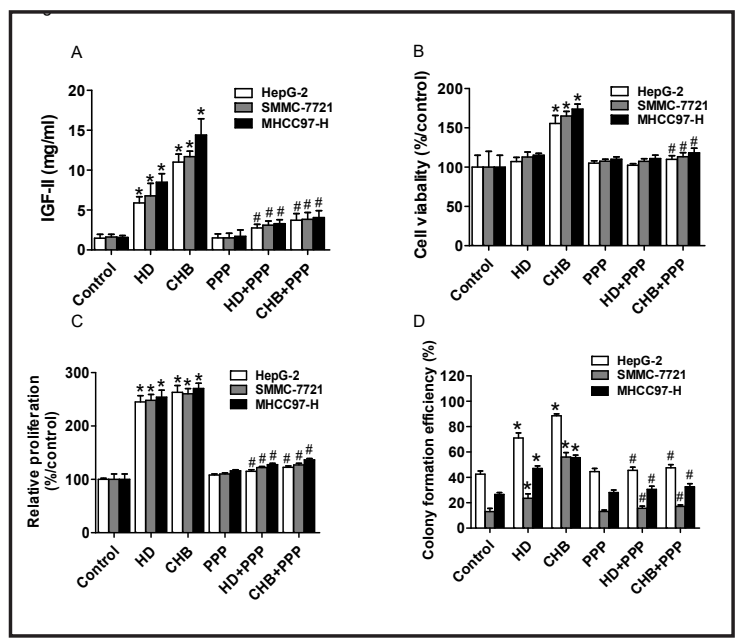

Fig. 6. Serum from $\mathrm{CHB}$ induces HRP-2 and NUPR1 mRNA and protein expression via IGF-IR in HCC cell lines (HepG-2, SMMC7721, MHCC97-H). Cells were pretreated with PPP $(10 \mu \mathrm{M})$ for $1 \mathrm{~h}$ and stimulated with serum from HDs and CHB patients for $48 \mathrm{~h}$. (A) HRP-2 and NUPR1 mRNA levels were analyzed by quantitative real-time PCR after normalization to $\beta$-actin mRNA. (B) HRP-2 and NUPR1 protein expression levels were measured by western blot. Data are presented as the mean \pm SEM from three independent experiments. Statistical significance was calculated using Student's t test. ${ }^{* *} \mathrm{p}<0.01$ vs. control; ${ }^{\# \#} \mathrm{p}<0.01$ vs. PPP.

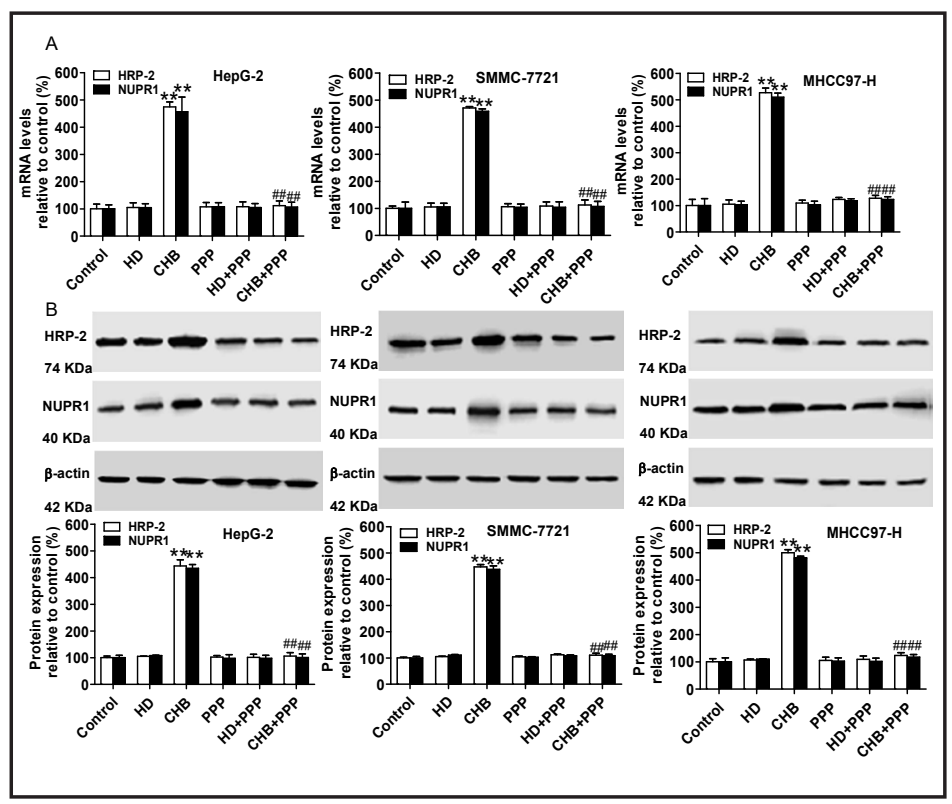


Fig. 7. Effect of IGF-II siRNA on HDs and CHB patient serum-induced cell proliferation in HCC cell lines (HepG-2, SMMC-7721, MHCC97$\mathrm{H})$. After application of negative control siRNA (NC siRNA) or IGF-II siRNA for $48 \mathrm{~h}$, cells were stimulated with serum from HDs and CHB patients for $48 \mathrm{~h}$. (A) mRNA levels of IGF-II in HCC cell lines were analyzed by RT-PCR and quantitative real-time PCR. (B) Protein expression levels of IGF-II in HCC cell lines were detected by western blot. (C) The relative proliferation of HCC cell lines was assayed by BrdU ELISA. Data are presented as the mean \pm SEM from three independent experiments. Significance was determined by two-way ANOVA or Student's t test. ${ }^{*} \mathrm{p}<0.05,{ }^{* *} \mathrm{p}<0.01$,
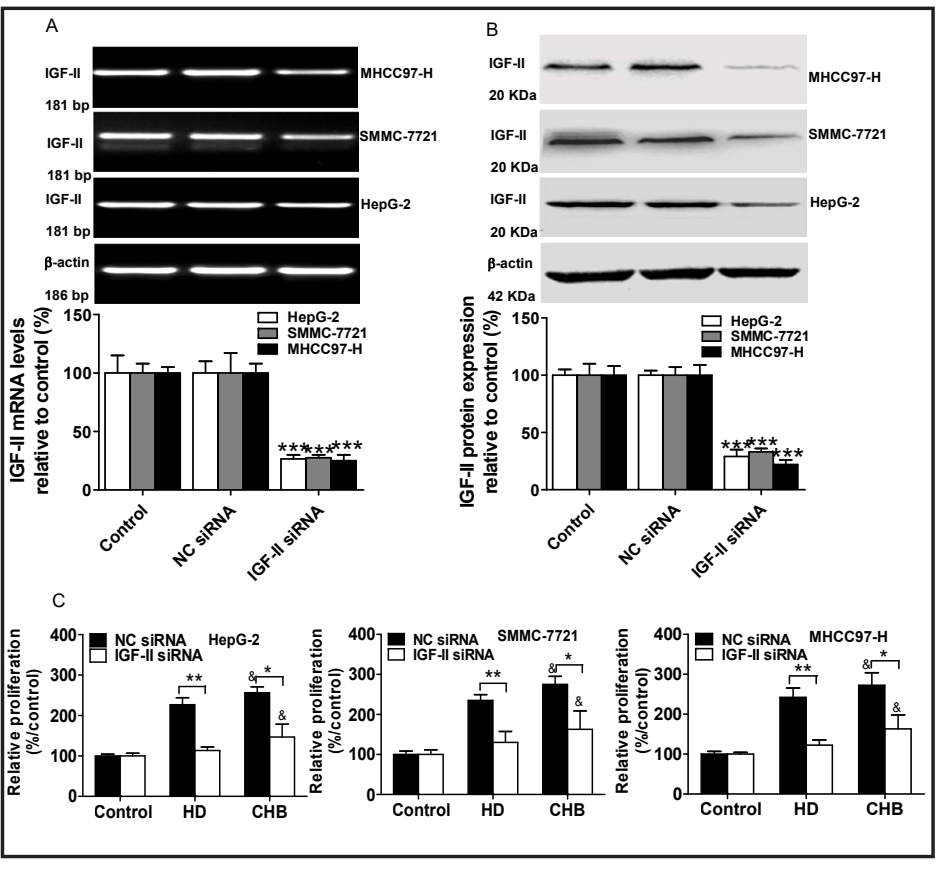
${ }^{* * *} \mathrm{p}<0.001$ vs. NC siRNA; ${ }^{\&} \mathrm{p}<0.05$ vs. HDs.

enhanced cell proliferation via IGF-II. As shown in Fig. 8, compared with the negative control, stimulation of cells with serum from CHB patients increased HRP-2 and NUPR1 mRNA and protein expression in HCC cell lines, whereas a lack of IGF-II dramatically decreased the inductive effects of serum from CHB patients on HRP-2 and NUPR1 mRNA and protein expression, again indicating that serum from CHB patients enhanced HRP-2 and NUPR1 mRNA and protein expression via IGF-II.

Serum from CHB patients induces ERK phosphorylation via IGF-IR in HCC cell lines

To evaluate the downstream effector of IGF-IR, cells were pretreated with the IGF-IR inhibitor PPP $(10 \mu \mathrm{M})$ for $1 \mathrm{~h}$ and subsequently stimulated with serum from HDs and CHB patients for 2 h; ERK and PI3K phosphorylation was then assessed. As shown in Fig. 9, serum from CHB patients significantly induced ERK phosphorylation but had no effect on PI3K phosphorylation. In addition, $10 \mu \mathrm{M}$ of PPP clearly decreased the inductive effects of serum from CHB patients on ERK phosphorylation in HCC cell lines. Therefore, these results demonstrated that serum from CHB patients induced ERK phosphorylation via IGF-IR in HCC cell lines.

Serum from HDs and CHB patients induces IGF-II secretion, cell proliferation, and HRP-2 and NUPR1 protein expression via MEK/ERK in HCC cell lines

After PD98059 became available as a highly specific inhibitor of MEK1 activation, it has typically been used as a selective, cell permeable inhibitor of the MEK/ERK pathway [20]. To clarify whether serum from HDs and CHB patients induced IGF-II secretion, cell proliferation, and HRP-2 and NUPR1 protein expression via ERK in HCC cell lines, cells were pretreated with the MEK inhibitor PD98059 $(1 \mu \mathrm{M})$ for $1 \mathrm{~h}$ and subsequently stimulated with serum from HDs and CHB patients for $48 \mathrm{~h}$. As shown in Fig. 10A and B, $1 \mu \mathrm{M}$ of PD98059 dramatically attenuated the inductive effect of serum from HDs and CHB patients on IGF-II secretion and cell proliferation in HCC cell lines. Accordingly, these results demonstrated 
Fig. 8. Effect of IGF-II siRNA on the inductive effects of serum from HDs and CHB patients on HRP-2 and NUPR1 mRNA and protein expression in HCC cell lines (HepG-2, SMMC-7721, MHCC97-H). After application of negative control siRNA (NC siRNA) or IGF-II siRNA for 48 $h$, cells were stimulated with serum from HDs and CHB patients for 48 h. (A and B) mRNA levels of HRP-2 and NUPR1 in HCC cell lines were analyzed by RT-PCR and quantitative real-time PCR. (C and D) HRP-2 and NUPR1 protein expression levels were measured by western blot. Data are presented as the mean \pm SEM from three independent experiments. Statistical significance was calculated using Student's t test. ${ }^{*} \mathrm{p}<0.05$ vs. NC siRNA.

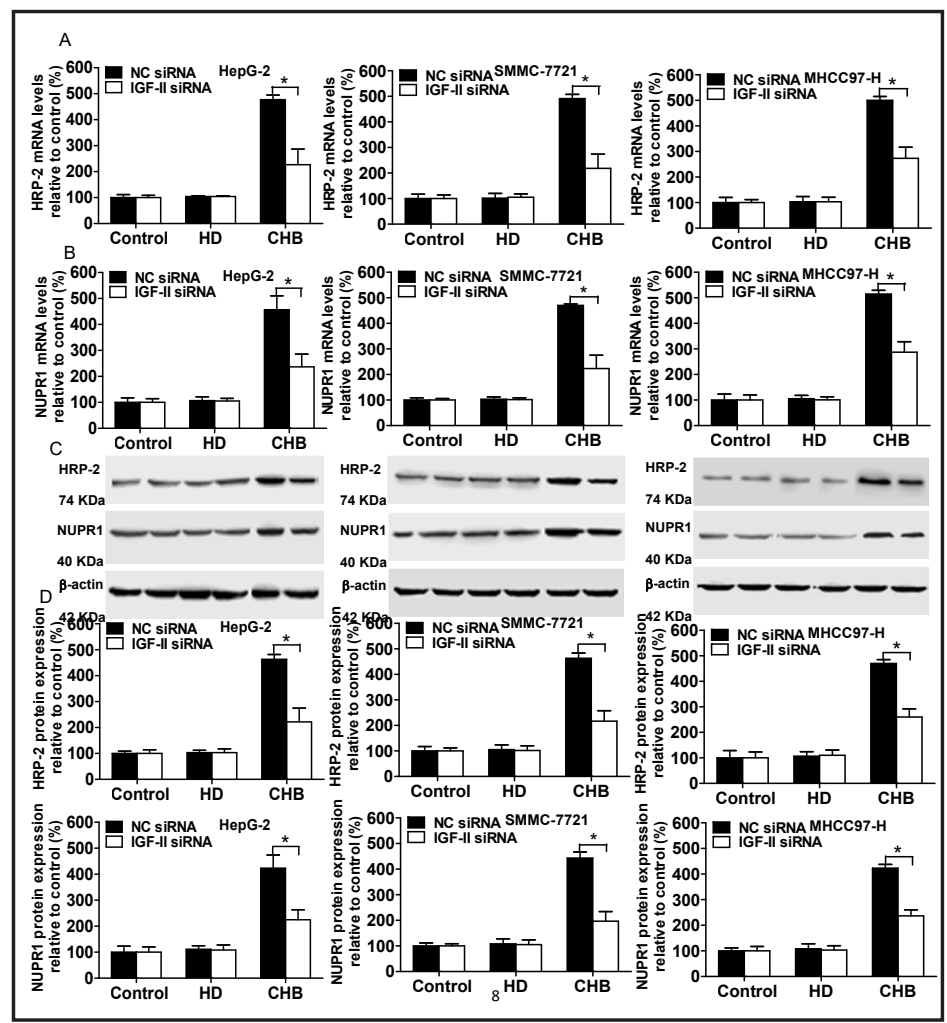

Fig. 9. Serum from CHB patients induces ERK phosphorylation via IGF-IR in HCC cell lines (HepG-2, SMMC-7721, MHCC97-H). Cells were pretreated with PPP $(10 \mu \mathrm{M})$ for $1 \mathrm{~h}$ and stimulated with serum from HDs and CHB patients for $2 \mathrm{~h}$. ERK and PI3K protein expression and phosphorylation were measured by western blot. Data are presented as the mean \pm SEM from three independent experiments. Statistical significance was calculated using Student's t test. ${ }^{*} \mathrm{p}<0.05$ vs. control; ${ }^{*} \mathrm{p}<0.05$ vs.

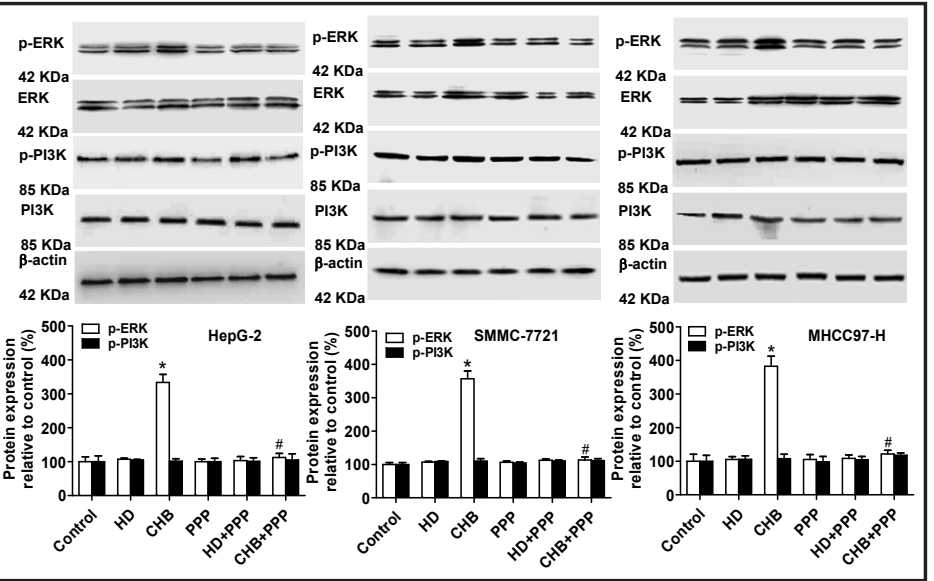
PPP.

that serum from HDs and CHB patients induced IGF-II secretion and cell proliferation via MEK/ERK in HCC cell lines. Moreover, $1 \mu \mathrm{M}$ of PD98059 significantly decreased the inductive effect of serum from CHB patients on HRP-2 and NUPR1 mRNA and protein expression in HCC cell lines. Consequently, these results also suggested that serum from CHB patients induced HRP-2 and NUPR1 mRNA and protein expression via MEK/ERK in HCC cells.

\section{Discussion}

In this study, we showed that the serum levels of IGF-II and IGF-IR were significantly higher in CHB patients than in HDs. We also found that serum from CHB patients directly 
Fig. 10. Serum from HDs and CHB patients induces IGF-II secretion, cell proliferation, and HRP-2 and NUPR1 protein expression via ERK in HCC cell lines (HepG-2, SMMC-7721, MHCC97$\mathrm{H})$. Cells were pretreated with PD98059 $(1 \mu \mathrm{M})$ for $1 \mathrm{~h}$ and stimulated with serum from HDs and CHB for 48 h. (A) IGF-II concentrations in the supernatant were measured by ELISA. (B) The relative proliferation of HCC cell lines was assayed by BrdU ELISA. (C) HRP-2 and NUPR1 protein expression levels were measured by western blot. Data are presented as the mean \pm SEM from three independent experiments. Statistical significance was calculated using one-way ANOVA or Student's t test. ${ }^{*} \mathrm{p}<0.05,{ }^{* *} \mathrm{p}<0.01$ vs. control; ${ }^{\#} \mathrm{p}<0.05,{ }^{\#} \mathrm{p}<0.01$ vs. PD98059;

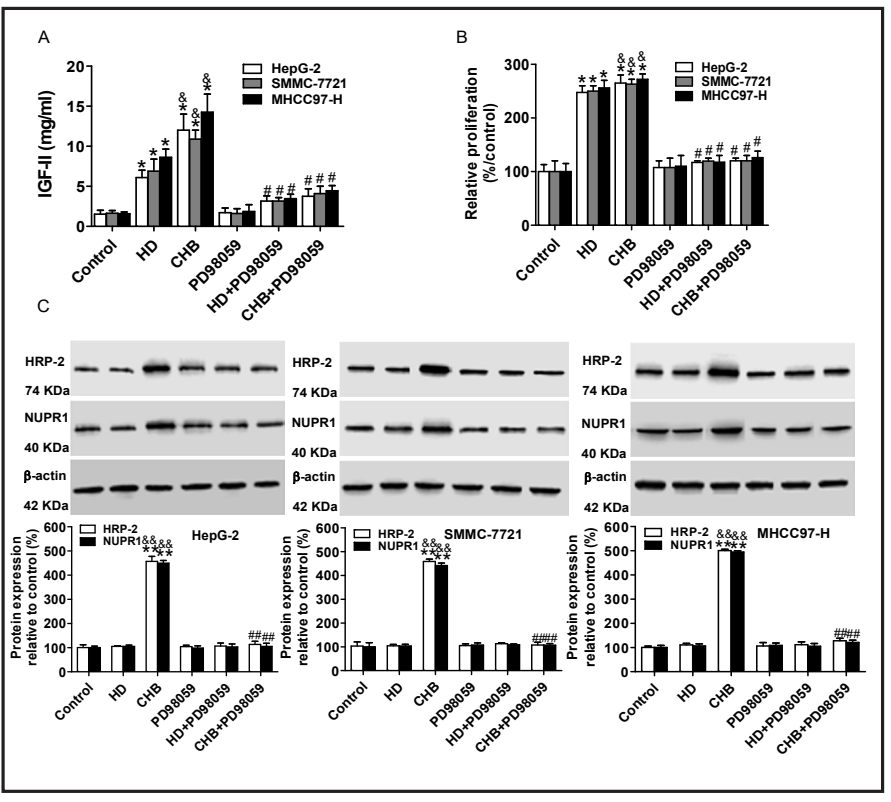
${ }^{\&} \mathrm{p}<0.05,{ }^{\& \&} \mathrm{p}<0.01$ vs. HDs.

induced cell growth, proliferation, IGF-II secretion, and HRP-2 and NUPR1 mRNA and protein expression in HCC cells. Moreover, serum from CHB patients increased IGF-II-induced cell growth, proliferation, and HRP-2 and NUPR1 mRNA and protein expression in HCC cells. Interesting, blockade of IGF-IR clearly inhibited the above effects. Most importantly, interference with IGF-II markedly repressed cell proliferation and HRP-2 and NUPR1 mRNA and protein expression induced by serum from CHB patients in HCC cells. Our findings further demonstrated that serum from CHB patients induced ERK phosphorylation via IGF-IR in HCC cell lines and that the MEK inhibitor PD98059 significantly decreased the inductive effects of serum from CHB patients on IGF-II secretion, cell proliferation, and HRP-2 and NUPR1 mRNA and protein expression in HCC cells. Taken together, these effects may be mediated by the IGF-II/IGF-IR/MEK/ERK signaling pathway in HCC cells.

HBV infection plays a central role in the etiology of HCC [21]. Many findings implicate IGF-II as a major risk factor in the growth and development of HCC [22]. Most studies have focused on HBV and HCC. However, little is known about how HBV increases the production of IGF-II and promotes the growth and viability of HCC cells. In the present study, we assessed the levels of circulating IGF-II and IGF-IR in HDs and CHB patients. The results showed that the serum levels of IGF-II and IGF-IR were significantly higher in CHB patients than in HDs, suggesting that there might be a close relationship between HBV and IGF-II. Next, to investigate the role of serum from CHB patients in HCC cells, we selected three different HCC cell lines (HepG-2, SMMC-7721, and MHCC97-H) and carefully evaluated the direct effects of serum from CHB patients on their cell growth and proliferation. Serum from CHB patients significantly increased cell growth and proliferation on MTT, BrdU ELISA, and plate colony formation assays. Based on the above results, we further found that serum from CHB patients increased IGF-II-induced cell growth, proliferation, and HRP-2 and NUPR1 mRNA and protein expression in HCC cells. Therefore, it is likely that IGF-II could link HBV infection with the cell growth and proliferation of HCC.

HDGF-related protein-2 (HRP-2) belongs to the family of HRPs. HDGF is the founding member of this family and is the most extensively studied [23]. It was originally purified from conditioned media of the human hepatoma cell line Huh-7 and was shown to be capable of stimulating the proliferation of Swiss 3T3 cells [24, 25]. Many studies have reported that HDGF is overexpressed and plays an important role in the development and progression of 
various types of human cancers [26-28]. A recent study showed that HRP-2 is frequently overexpressed in human HCC tissues and is required for HCC cell growth in vitro and in vivo [29]. In the present study, we found that serum from CHB patients enhanced HRP-2 mRNA and protein expression and increased IGF-II-induced HRP-2 mRNA and protein expression in HCC cells. These results primarily reveal that HBV infection could promote cell growth and proliferation by inducing HRP-2 overexpression in HCC cells.

NUPR1 was originally identified as p8 [30], a gene that is preferentially upregulated in response to cellular stress during the acute phase of pancreatitis in the rat. In the liver, NUPR1 is an important element in the hepatocyte stress response after hepatic injury by CCl4 [31]. NUPR1 has also been identified as a key regulator and metabolic switch in response to mitochondrial damage during liver cancer progression [32]. In addition, NUPR1 is activated by HBx protein and mediates the cell growth and survival of HBV-positive cells [33]. A recent study also confirmed that NUPR1 plays a critical role in the regulation of the tumor cell growth, tumor migration, and invasive capacity of HCC cells, suggesting its oncogenic role in HCC [34]. In the present study, we found that serum from CHB patients increased NUPR1 mRNA and protein expression and promoted IGF-II-induced NUPR1 mRNA and protein expression in HCC cells. These data primarily show that HBV infection could enhance cell growth and proliferation by inducing NUPR1 overexpression in HCC cells.

IGF-II, an autocrine growth factor, is highly expressed in many tumors and tumor cell lines [35]. IGF-II exerts biological actions primarily by binding to and activating IGFIR. Emerging evidence confirms that IGF-II is associated with proliferation, migration, and invasion in HCC $[13,36]$. HBx is a multifunctional regulatory protein closely linked to HCC. HBx upregulates the expression of IGF-II in premalignant proliferative nodules and of IGFIR in hepatoma cell lines [11,37]. Our data showed that the serum levels of IGF-II and IGFIR were significantly higher in CHB patients than in HDs. Furthermore, serum from CHB patients directly induced IGF-II secretion in HCC cells, implying that HBV-related factors, particular IGF-II, may increase cell growth and proliferation in an IGF-II signaling pathwaydependent manner. Next, blockade of IGF-IR in HCC cells clearly inhibited cell growth, proliferation, IGF-II secretion, and HRP-2 and NUPR1 mRNA and protein expression induced by the serum of CHB patients. Most importantly, interference with IGF-II markedly repressed the cell proliferation and HRP-2 and NUPR1 mRNA and protein expression induced by CHB patient serum in HCC cells. Therefore, we can conclude that HBV might act as an important factor in the growth and proliferation of HCC via the activation of IGF-II/IGF-IR signaling.

IGF-II interacts with IGF-IR, causing downstream activation of PI3K/Akt signaling and finally leading to protein translation and proliferation [38]. Besides the major pathway, IGFIR may also activate p38 mitogen-activated protein kinase (p38 MAPK) to induce cell growth and differentiation [39]. ERK also plays a pivotal role in cell proliferation and metastasis during various stages of cancer [40]. After ERK phosphorylation, it translocates to the nucleus, where it leads to changes in gene expression and regulates various transcription factors [41]. A previous study indicated that HBx-induced oval cell proliferation is dependent on activation of the MEK/ERK and PI3K/Akt signaling pathways [42]. Moreover, a recent study demonstrated that $\mathrm{HBcAg}$ activates p38, ERK, and NF- $\kappa \mathrm{B}$ to enhance the production of IL-6 in hepatocytes [43]. To further evaluate the downstream effectors of IGF-IR, HCC cells were pretreated with the IGF-IR inhibitor PPP and subsequently stimulated with serum from HDs and CHB patients. We found that serum from CHB patients significantly induced ERK phosphorylation but had no effect on PI3K phosphorylation. Moreover, the IGF-IR inhibitor PPP clearly inhibited the inductive effects of serum from CHB patients on ERK phosphorylation in HCC cell lines, suggesting that serum from CHB patients induced ERK phosphorylation via IGF-IR in HCC cell lines. However, we found that HD serum had no effect on ERK phosphorylation. Although the upstream activators MEK1 and MEK2 were not observed, it seems plausible that HD serum could cause MEK1 and MEK2 activation. Finally, the MEK inhibitor PD98059 partly diminished CHB patient serum-induced cell proliferation and HRP-2 and NUPR1 expression in HCC cell lines. It seems reasonable to conclude that ERK translocates to the nucleus to induce downstream gene targets, including the pro- 


\section{Cellular Physiology Cell Physiol Biochem 2018;47:39-53 \begin{tabular}{l|l} 
DOI: 10.1159/000489744 & and Biochemistry \\
Published online: May 15, 2018 & $\begin{array}{l}\text { O 2018 The Author(s). Published by S. Karger AG, Basel } \\
\text { www.karger.com/cpb }\end{array}$
\end{tabular} Ji et al.: CHB Promotes Proliferation via IGF-II in HCC}

proliferative proteins HRP-2 and NUPR1. Thus, activation of ERK ultimately enhances the proliferation of HCC cells.

In conclusion, our study revealed that serum from CHB patients increased cell growth and proliferation as well as enhanced HRP-2 and NUPR1 expression in HCC cells via the IGF-II/IGF-IR/MEK/ERK signaling pathway. These findings will help us to understand the molecular mechanisms underlying HBV-related HCC and may lead to the development of effective therapies in the future.

\section{Acknowledgements}

This work was supported by a grant from the National Natural Science Foundation of China (No. 81201925), Natural Science Foundation of Shaanxi Province (No. 2017JM8001), Key Research and Development Plan of Shaanxi Province (No. 2017SF-313), the Fundamental Research Funds for the Central Universities of China (No. XJJ2017072), and Personnel Training Specialized Research Foundation of the Second Affiliated Hospital of Xi'an Jiaotong University of China (Nos. RC(GG)201404 and RC(GG)201502).

\section{Disclosure Statement}

The authors declare to have no conflict of interests.

\section{References}

1 Zhang T, Zhang J, You X, Liu Q Du Y, Gao Y, Shan C, Kong G, Wang Y, Yang X, Ye L, Zhang X: Hepatitis B virus $\mathrm{X}$ protein modulates oncogene Yes- associated protein by CREB to promote growth of hepatoma cells. Hepatology 2012;56:2051-2059.

-2 Okamoto Y, Shinjo K, Shimizu Y, Sano T, Yamao K, Gao W, Fujii M, Osada H, Sekido Y, Murakami S, Tanaka Y, Joh T, Sato S, Takahashi S, Wakita T, Zhu J, Issa JP, Kondo Y: Hepatitis virus infection affects DNA methylation in mice with humanized livers. Gastroenterology 2014;146:562-572.

3 Singal AG, El-Serag HB: Hepatocellular carcinoma from epidemiology to prevention: translating knowledge into practice. Clin Gastroenterol Hepatol 2015;13:2140-2151.

4 Parkin DM: The global health burden of infection-associated cancers in the year 2002. Int J Cancer 2006;118:3030-3044.

5 Parikh P, Ryan JD, Tsochatzis EA: Fibrosis assessment in patients with chronic hepatitis B virus (HBV) infection. Ann Transl Med 2017;5:40.

-6 Tang H, Oishi N, Kaneko S, Murakami S: Molecular functions and biological roles of hepatitis B virus X protein. Cancer Sci 2006;97:977-983.

7 Martin-Vilchez S, Lara-Pezzi E, Trapero-Marugán M, Moreno-Otero R, Sanz- Cameno P: The molecular and pathophysiological implications of hepatitis B X antigen in chronic hepatitis B virus infection. Rev Med Virol 2011;21:315-329.

8 Murakami S: Hepatitis B virus x protein: A multifunctional viral regulator. J. Gastroenterol 2001;36:651660.

9 Rawat S, Clippinger AJ, Bouchard MJ: Modulation of apoptotic signaling by the hepatitis B virus x protein. Viruses 2012;4:2945-2972.

10 Tang SH, Yang DH, Huang W, Zhou M, Zhou HK, Lu XH, Ye G: Differential promoter usage for insulin-like growth factor-II gene in Chinese hepatocellular carcinoma with hepatitis B virus infection. Cancer Detect Prev 2006;30:192-203.

11 d'Arville CN, Nouri-Aria KT, Johnson P, Williams R: Regulation of insulin-like growth factor II gene expression by hepatitis B virus in hepatocellular carcinoma. Hepatology 1991;13:310-315. 


\section{Cellular Physiology Cell Physiol Biochem 2018;47:39-53 \begin{tabular}{l|l} 
and Biochemistry Publisned onlIne: IVay 15, 2018 & $\begin{array}{l}\text { (c) } 2018 \text { The Author(s). Published by S. Karger AG, Basel } \\
\text { www.karger.com/cpb }\end{array}$
\end{tabular}}

Ji et al.: CHB Promotes Proliferation via IGF-II in HCC

12 Yao N, Yao D, Wang L, Dong Z, Wu W, Qiu L, Yan X, Yu D, Chen J, Sai W, Zhang H, Yang J: Inhibition of autocrine IGF-II on effect of human HepG2 cell proliferation and angiogenesis factor expression. Tumour Biol 2012;33:1767-1776.

13 Nussbaum T, Samarin J, Ehemann V, Bissinger M, Ryschich E, Khamidjanov A, Yu X, Gretz N, Schirmacher $\mathrm{P}$, Breuhahn K: Autocrine insulin-like growth factor-II stimulation of tumor cell migration is a progression step in human hepatocarcinogenesis. Hepatology 2008;48:146-156.

14 Ji YY, Wang ZD, Li ZF, Huang N, Chen HY, Li BH, Hui B: Silencing IGF-II impairs C-myc and N-ras expressions of SMMC-7721 cells via suppressing FAK/PI3K/Akt signaling pathway. Cytokine 2017;90:44-53.

15 Wang Z, Zhou J, Fan J, Tan CJ, Qiu SJ, Yu Y, Huang XW, Tang ZY: Sirolimus inhibits the growth and metastatic progression of hepatocellular carcinoma. J Cancer Res Clin Oncol 2009;135:715-722.

16 Di Bernardo G, Messina G, Capasso S, Del Gaudio S, Cipollaro M, Peluso G, Casale F, Monda M, Galderisi U: Sera of overweight people promote in vitro adipocyte differentiation of bone marrow stromalcells. Stem Cell Res Ther 2014;5:4.

17 Hankey DP, McCabe RE, Doherty MJ, Nolan PC, McAlinden MG, Nelson J, Wilson DJ: Enhancement of human osteoblast proliferation and phenotypic expression when cultured in human serum. Acta Orthop Scand 2001;72:395-403.

18 Lai WL, Hung WY, Wong LL, Yuan Z, Leong VY, Lee JM, Ng IO, Jin DY, Ching YP: The centrosomal protein Tax1 binding protein 2 is a novel tumor suppressor in hepatocellular carcinoma regulated by cyclin-dependent kinase 2 Hepatology 2012;56:1770-1781.

19 Ji YY, Wang ZD, Li ZF, Zhang AJ, Jin YF, Chen HY, Le XF: Angiotensin II enhances proliferation and inflammation through AT1/PKC/NF- $\mathrm{B}$ signaling pathway in hepatocellular carcinoma cells. Cell Physiol Biochem 2016;39:13-32.

20 Dudley DT, Pang L, Decker SJ, Bridges AJ, Saltiel AR: A synthetic inhibitor of the mitogen-activated protein kinase cascade. Proc Natl Acad Sci USA 1995;92:7686-7689.

-21 Farazi PA, DePinho RA: Hepatocellular carcinoma pathogenesis: from genes to environment. Nat Rev Cancer 2006;6:674-687.

-22 Pollak M: Insulin and insulin-like growth factor signalling in neoplasia. Nat Rev Cancer. 2008;8:915-928.

23 Izumoto Y, Kuroda T, Harada H, Kishimoto T, Nakamura H: Hepatoma- derived growth factor belongs to a gene family in mice showing significant homology in the amino terminus. Biochem Biophys Res Commun 1997;238:26-32.

24 Nakamura H, Kambe H, Egawa T, Kimura Y, Ito H, Hayashi E, Yamamoto H, Sato J, Kishimoto S: Partial purification and characterization of human hepatoma-derived growth factor. Clin Chim Acta 1989;183:273284.

25 Nakamura H, Izumoto Y, Kambe H, Kuroda T, Mori T, Kawamura K, Yamamoto H, Kishimoto T: Molecular cloning of complementary DNA for a novel human hepatoma-derived growth factor. Its homology with high mobility group-1 protein. J Biol Chem 1994;269:25143-25149.

-26 Zhang J, Ren H, Yuan P, Lang W, Zhang L, Mao L: Down-regulation of hepatoma-derived growth factor inhibits anchorage-independent growth and invasion of non-small cell lung cancer cells. Cancer Res 2006;66:18-23.

-27 Uyama H, Tomita Y, Nakamura H, Nakamori S, Zhang B, Hoshida Y, Enomoto H, Okuda Y, Sakon M, Aozasa K, Kawase I, Hayashi N, Monden M: Hepatoma-derived growth factor is a novel prognostic factor for patients with pancreatic cancer. Clin Cancer Res 2006;12:6043-6048.

-28 Yamamoto S, Tomita Y, Hoshida Y, Takiguchi S, Fujiwara Y, Yasuda T, Doki Y, Yoshida K, Aozasa K, Nakamura H, Monden M: Expression of hepatomaderived growth factor is correlated with lymph node metastasis and prognosis of gastric carcinoma. Clin Cancer Res 2006;12:117-122.

29 Gao K, Xu C, Jin X, Wumaier R, Ma J, Peng J, Wang Y, Tang Y, Yu L, Zhang P: HDGF-related protein-2 (HRP2) acts as an oncogene to promote cell growth in hepatocellular carcinoma. Biochem Biophys Res Commun 2015;458:849-855.

-30 Mallo GV, Fiedler F, Calvo EL, Ortiz EM, Vasseur S, Keim V, Morisset J, Iovanna JL: Cloning and expression of the rat p8 cDNA, a new gene activated in pancreas during the acute phase of pancreatitis, pancreatic development, and regeneration, and which promotes cellular growth. J Biol Chem 1997;272:32360-32369. 


\section{Cellular Physiology Cell Physiol Biochem 2018;47:39-53 \begin{tabular}{l|l} 
DOI: 10.1159/000489744 & and Biochemistry \\
Publisned 2018 The Author(s). Published by S. Karger AG, Basel \\
www.karger.com/cpb
\end{tabular}}

Ji et al.: CHB Promotes Proliferation via IGF-II in HCC

31 Taïeb D, Malicet C, Garcia S, Rocchi P, Arnaud C, Dagorn JC, Iovanna JL, Vasseur S: Inactivation of stress protein p8 increases murine carbon tetrachloride hepatotoxicity via preserved CYP2E1 activity. Hepatology 2005;42:176-182.

-32 Lee YK, Jee BA, Kwon SM, Yoon YS, Xu WG, Wang HJ, Wang XW, Thorgeirsson SS, Lee JS, Woo HG, Yoon G: Identification of a mitochondrial defect gene signature reveals NUPR1 as a key regulator of liver cancer progression. Hepatology 2015;62:1174-1189.

-33 Bak Y, Shin HJ, Bak IS, Yoon DY, Yu DY: Hepatitis B virus X promotes hepatocellular carcinoma development via nuclear protein 1 pathway. Biochem Biophys Res Commun 2015;466:676-681.

-34 Emma MR, Iovanna JL, Bachvarov D, Puleio R, Loria GR, Augello G, Candido S, Libra M, Gulino A, Cancila V, McCubrey JA, Montalto G, Cervello M: NUPR1, a new target in liver cancer: implication in controlling cell growth, migration, invasion and sorafenib resistance. Cell Death Dis 2016;7:e2269.

-35 Foulstone E, Prince S, Zaccheo O, Burns JL, Harper J, Jacobs C, Church D and Hassan AB: Insulin-like growth factor ligands, receptors, and binding proteins in cancer. J Pathol 2005;205:145-153.

-36 Pivonello C, Negri M, De Martino MC, Napolitano M, de Angelis C, Provvisiero DP, Cuomo G, Auriemma RS, Simeoli C, Izzo F, Colao A, Hofland LJ, Pivonello R: The dual targeting of insulin and insulinlike growth factor 1 receptor enhances the mTOR inhibitor-mediated antitumor efficacy in hepatocellular carcinoma. Oncotarget 2016;7:9718-9731.

37 Kim SO, Park JG and Lee YI: Increased expression of the insulin-like growth factor I (IGF-I) receptor gene in hepatocellular carcinoma cell lines: implications of IGF-I receptor gene activation by hepatitis B virus X gene product. Cancer Res1996;56:3831-3836.

38 Suvasini R, Shruti B, Thota B, Shinde SV, Friedmann-Morvinski D, Nawaz Z, Prasanna KV, Thennarasu K, Hegde AS, Arivazhagan A, Chandramouli BA, Santosh V, Somasundaram K: Insulin growth factor-2 binding protein 3 (IGF2BP3) is a glioblastoma-specific marker that activates phosphatidylinositol 3-kinase/mitogen-activated protein kinase (PI3K/MAPK) pathways by modulating IGF-2 J Biol Chem 2011;286:25882-25890.

39 Héron-Milhavet L, Karas M, Goldsmith CM, Baum BJ, LeRoith D: Insulin-like growth factor-I (IGF-I) receptor activation rescues UV-damaged cells through a p38 signaling pathway. Potential role of the IGF-I receptor in DNA repair. J Biol Chem 2001;276:18185-18192.

40 Roberts PJ, Der CJ: Targeting the Raf-MEK-ERK mitogen-activated protein kinase cascade for the treatment of cancer. Oncogene 2007;26:3291-3310.

41 Asati V, Mahapatra DK, Bharti SK: PI3K/Akt/mTOR and Ras/Raf/MEK/ERK signaling pathways inhibitors as anticancer agents: Structural and pharmacological perspectives. Eur J Med Chem 2016;109:314-341.

42 Wang HY, Yang SL, Liang HF, Li CH: HBx protein promotes oval cell proliferation by up-regulation of cyclin D1 via activation of the MEK/ERK and PI3K/Akt pathways. Int J Mol Sci 2014;15:3507-3518.

43 Chen Z, Li YX, Fu HJ, Ren YL, Zou L, Shen SZ, Chen P, Sun T, Huang CH: Hepatitis B virus core antigen stimulates IL-6 expression via p38, ERK and NF- $\kappa B$ pathways in hepatocytes. Cell Physiol Biochem 2017;41:91-100. 